\title{
HYPERNATRAEMIA IN EXTRARENAL URAEMIA
}

\section{BY}

\author{
JOAN F. ZILVA AND J. N. HARRIS-JONES \\ From the Royal Infirmary and Royal Hospital, Sheffield
}

(RECEIVED FOR PUBLICATION MARCH 28, 1956)

Our knowledge of the mechanisms responsible for sodium retention is still incomplete, and the number of clinical conditions of which it is known to be a feature is constantly being increased. The cases reported here show a pattern of hypernatraemia which, so far as we know, has not been reported previously. Because these patients were admitted as emergencies, and their potential interest was unrecognized at first, the data are less complete than might have been wished, but the electrolyte patterns seemed sufficiently unusual to merit publication.

\section{Case Reports}

Case 1.-A woman aged 59 years was admitted with a history of headache for nine weeks, accompanied by severe mental derangement for 10 days before admission. There was no previous history of renal disease nor of any significant illness. On examination, she was disorientated, but there were no other abnormal signs in the central nervous or other systems. Her blood pressure was $170 / 90 \mathrm{~mm}$. Hg. Some days after her admission her condition deteriorated rapidly. She was now comatose and obviously dehydrated, and the blood pressure had fallen to $95 / 70 \mathrm{~mm}$. $\mathrm{Hg}$. The urine showed evidence of heavy infection with Bact. coli. The results of the serum and plasma electrolyte estimations and blood urea are shown in Fig. 1, where the subsequent estimations are also recorded.

After rehydration with $5 \%$ glucose intravenously, treatment with Bull, Joekes, and Lowe's (1949) modification of the Borst (1948) régime was instituted with antibiotic treatment for the urinary infection. Clinically there was a rapid improvement, with rehydration and a rise of blood pressure, but her mental state did not improve until the electrolyte pattern returned to normal.

After clinical recovery and sterilization of the urinary tract, urea clearance, water concentration and dilution tests, and intravenous pyelography were normal.

Case 2.-A woman aged 52 was admitted with a history of thirst, increasing oedema, and ascites due to cardiac failure. However, no abnormality was found in the cardiovascular system, and an E.C.G. was normal. The urine contained a light cloud of albumin
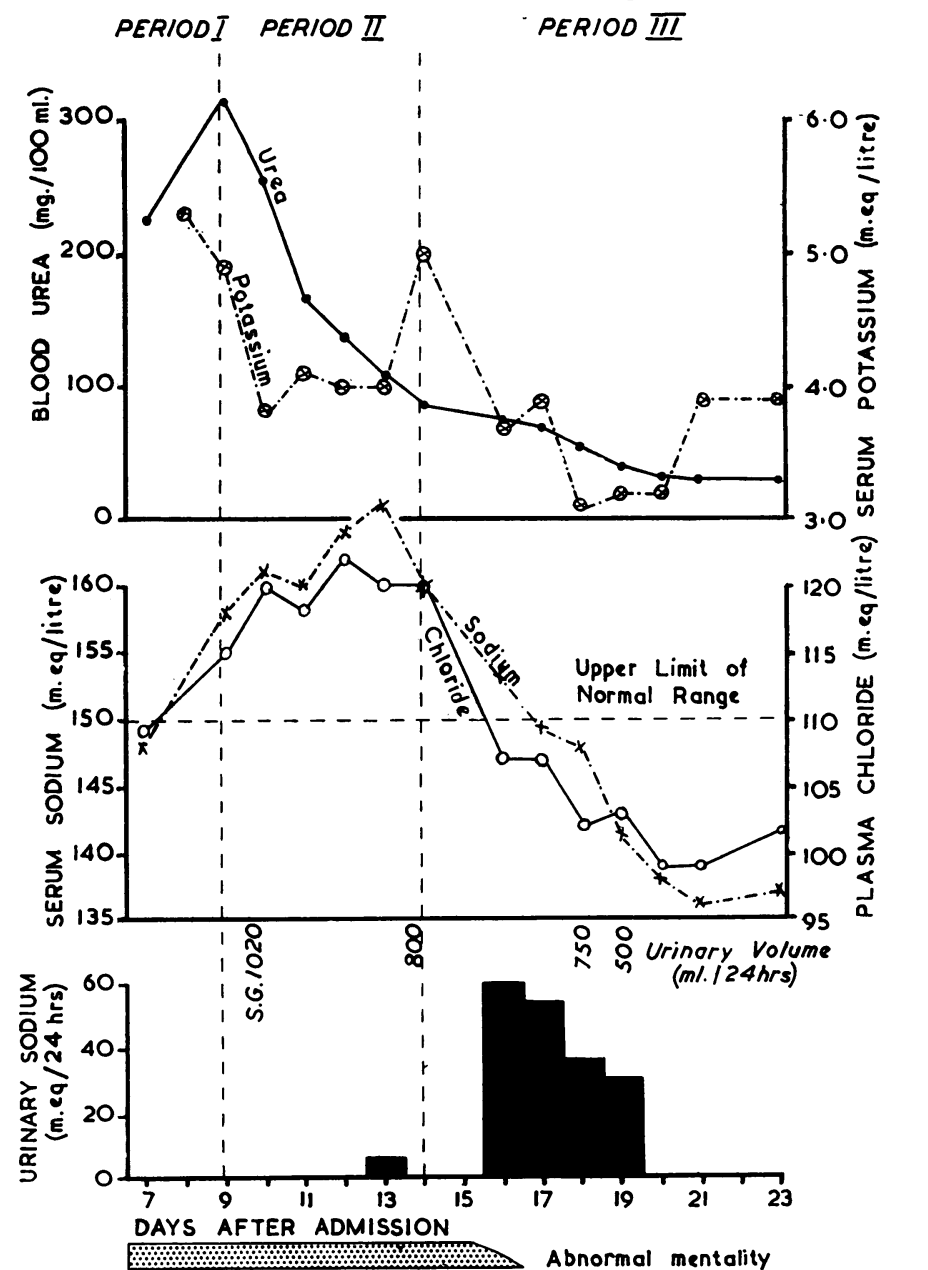

FIG. 1.-Case 1: Electrolyte_and_urea values. 


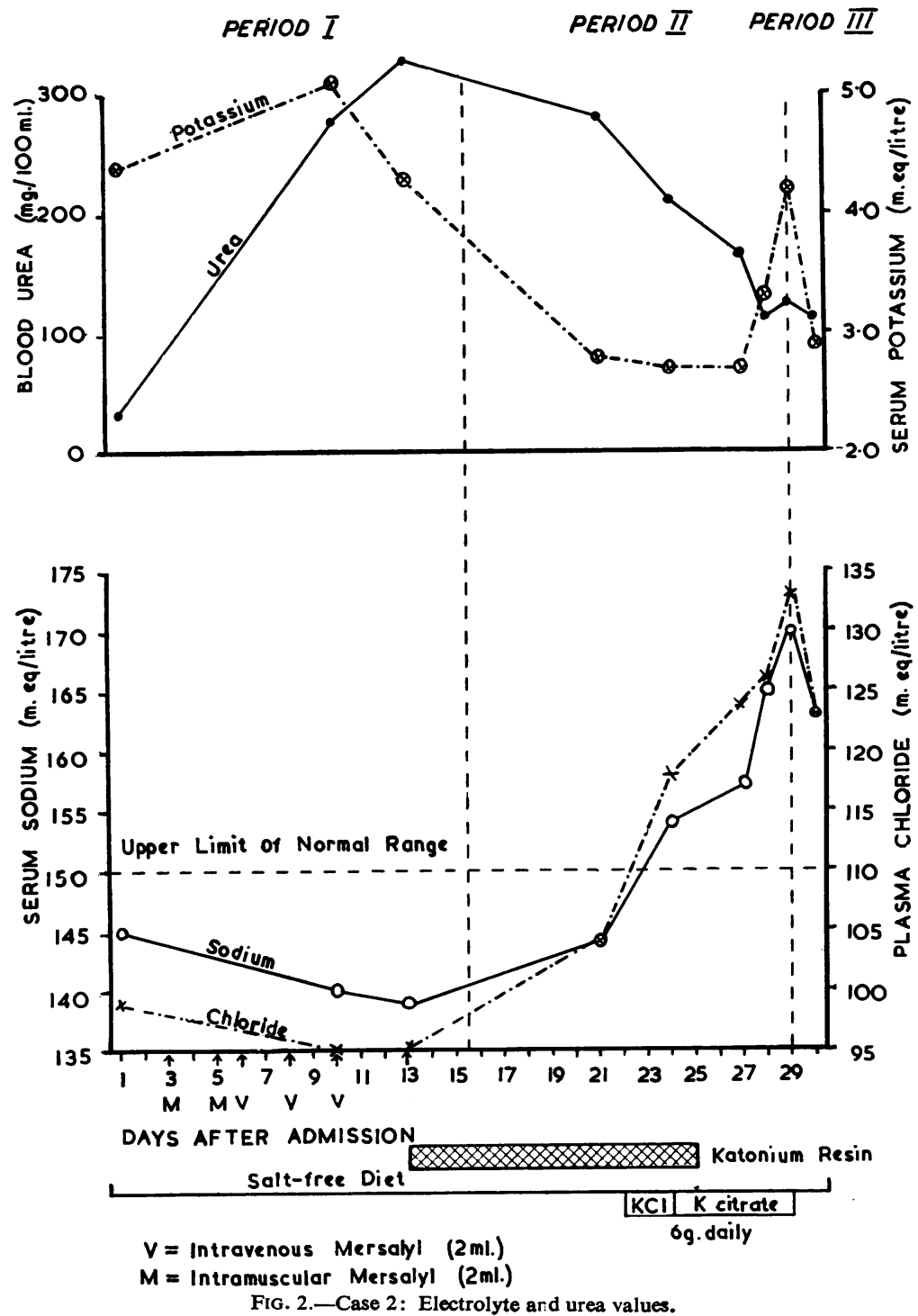

died of bronchopneumonia on the 31st day after admission.

Necropsy confirmed the presence of bronchopneumonia and showed a minute are a of cerebral softening in the left parietal region. The kidneys shared in the generalized oedema but were otherwise normal. Histological examination of the kidneys also failed to show any other abnormality. There was some atheroma of the coronary vessels, but the myocardium appeared normal.

Case 3.-A man of 68 years of age was admitted with a history of thrombophlebitis of the legs accompanied for 10 days before admission by retrosternal pain and dyspnoea. Examination showed him to be ill and dyspnoeic, and radiography revealed linear opacities in the left lung. He was considered to have had multiple pulmonary emboli, and treatment with anticoagulants, penicillin, and mercurial diuretics was started (Fig. 3).

The initial and subsequent estimations of the electrolytes and urea are shown in Fig. 3. The Bull modification of the Borst régime was begun on the second day; on the fifth day insulin and glucose were given in an attempt to lower the raised serum potassium level. The man's condition appeared to improve after four days of therapy, although some vomiting continued. However, on the sixth day after admission the patient died following a further attack of retrosternal pain and dyspnoea.

Post-mortem examination revealed a massive pulmonary embolus thought to have come from the femoral vein. The kidneys appeared normal on both macroscopic and histological examination.

\section{Urinary Ketosteroids}

The observation of the somewhat unusual electrolyte pattern in Case 1 led to an attempt to estimate the urinary 17-ketosteroid and ketogenic steroid output in Cases 2 and 3. This was difficult in Case 2 because of incontinence, but on day 29 the 17-ketogenic steroid content of the $215 \mathrm{ml}$. urine collected over 27 hours was $13.2 \mathrm{mg}$. and the $17-$ ketosteroid content $6.3 \mathrm{mg}$. Apart from the known gross incontinence, a a further effort to reduce the body sodium. Deterioration continued, and the patient 
creatinine content of only $0.43 \mathrm{~g}$. in this volume of urine and the rapidly falling blood urea suggest a much higher urinary output. From these considerations it would seem reasonable to assume that the true output of ketogenic steroids in this case was high. In Case 3 the 17ketogenic steroid output on days 4, 5, and 6 was $31.6,36.5$, and $19.4 \mathrm{mg} . / 24$ h o u r s respectively. The ketogenic steroids were estimated by the method of Gibson and Norymberski (1954). The normal adult range by this method is taken as $5.7-17.7 \mathrm{mg}$. $/ 24$ hours (Levell, Mitchell, Paine, and Jordan, 1957), and all these three figures fall above this range. The 17-ketosteroids were normal (13.6, 14.2, and $8.6 \mathrm{mg}$. $/ 24$ hours).

\section{Discussion}

As may be seen from the tables and charts, two of these patients showed strikingly similar electrolyte patterns and the third appeared to be following the same course. To facilitate discussion we have divided the course into three arbitrary periods.

Period 1.- The essential feature of this period is a rising blood urea associated with a fairly high serum potassium level. The serum sodium and chloride show little change in any of the patients. The clinical picture and electrolyte pattern during this period are indistinguishable from that of classical uraemia.

Period 2.-This phase is characterized by a falling blood urea and a rise in serum sodium and chloride, and, at least where results of analysis are available, a low urinary loss of sodium. The serum values rose to high levels in Case 2 in spite of a continued lowsodium diet and administration of a sodiumremoving cation exchange resin. A fall in serum potassium accompanied the rise in sodium and chloride.

Period 3.-This is shown only in Cases 1 and 2 . There is a continued fall of blood urea, and a now falling level of sodium and chloride in the blood coinciding with an increase in their urinary output. In both cases there was an initial abrupt rise in serum potassium, followed by a fall, and in Case 1 a gradual return to normal.

The striking feature of the overall picture is the very strong tendency to sodium and chloride retention after dehydration has been corrected and 
and Alexander, 1955), excessive administration of sodium in diabetic coma (Schoolman and Hoffman, 1955; Myers and Iseri, 1955), gastro-intestinal haemorrhage (Allott, 1939), and diabetes insipidus (Engstrom and Liebman, 1953). The only groups to be considered here are dehydration and acute renal lesions, and in only one of these cases was there. at any time, evidence of renal disease (Case 1). Case 2 was in congestive cardiac failure and hypernatraemia has been reported in this condition (Iseri, McCaughey, Alexander, Boyle, and Myers, 1952), but the serum sodium level was normal on admission, when failure was at its most severe, and rose after the latter had improved.

Welt et al. (1952) have described a series of cases in which dehydration, resulting from reduced water intake in the presence of large renal and insensible losses, led to hypernatraemia of a degree comparable to that in our cases. However, where they give figures for all serum values it is apparent that the levels of non-protein nitrogen, and usually of potassium, fluctuated in the same direction as those of the sodium and chloride, and that the potassium never showed the reciprocal fall seen in our cases. Pure water depletion may lead to hypernatraemia, but this occurs during the period of rising blood urea (Marriott, 1947). Moreover, none of our three cases could be described as examples of pure water depletion, for all must have lost chloride either from vomiting or from mercurial diuretics, or both, thus tending to lower the plasma chloride. We would like to stress again that the sodium and chloride retention occurred during the period of a falling blood urea and when the patient was clinically well hydrated. For these reasons we feel sure that dehydration can, at most, be a very secondary factor. However, the osmotic diuresis due to the high urinary urea may have prevented the masking of the hypernatraemia which might have resulted from reabsorption of water with the sodium.

Natelson and Alexander (1955) state that hypernatraemia is seen following severe dehydration, and Merrill (1954) also says that he has seen it during the diuresis after anuria. However, neither author provides details.

The fall of potassium which accompanied the rise in sodium and chloride suggests that the factor stimulating the tubules to reabsorb sodium and chloride might be of adrenocortical origin. Unfortunately it is only in Case 1 that we can be certain that the treatment had no specific effect on the serum potassium level. However, although in Case 2 oral potassium was administered for seven days, the serum level remained unchanged until the end of this period, when an abrupt rise coincided with a fall in serum sodium and chloride. In Case 3 we cannot be sure that the fall in serum potassium was not the result of specific measures taken to lower it, but the electrolyte pattern is so strikingly similar in all three patients that it appears likely, though by no means certain, that this fall of serum potassium is in keeping with that of Case 1.

It was for this reason that we attempted to estimate the 24-hour output of ketosteroids and ketogenic steroids in Cases 2 and 3. As stated above, the 17-ketosteroids were normal in both cases, but in Case 3 the output of ketogenic steroids was raised. Even without speculating on the true output in Case 2, it seems probable, from the electrolyte patterns, that there was adrenocortical overactivity in all three cases. It would have been interesting to know the aldosterone output in these cases. The closest analogy would appear to be that of post-operative retention of sodium (Le Quesne and Lewis, 1954) in which Llaurado (1955) had shown an increased excretion of aldosterone and in which the output of ketogenic steroids is known to be raised (Jepson, Jordan, and Levell, 1956).

An interesting point in Case 1 was that serum levels of sodium and chloride rose to figures higher than could be explained merely by retention of sodium, when the intake of sodium was negligible. It has been suggested that aldosterone stimulates transfer of sodium from cells to plasma (Prunty, McSwiney, and Mills, 1955), and this may be a possible explanation in this case. It is also possible that during the period of circulatory failure sodium entered the intracellular space in exchange for potassium, which is known to leave cells in congestive cardiac failure (Squires, Crosley, and Elkinton, 1951 ; Cort and Matthews, 1954) and as a result of tissue anoxia (Myers and Iseri, 1955). During recovery the reverse process would occur releasing sodium from the cells. Marked sodium uptake by the cells in anoxia has been demonstrated in vitro by Leaf (1956). Assuming an extracellular fluid volume of 15 litres and an intracellular fluid volume of 35 litres, it will be seen that a loss of only just over $4 \mathrm{~m}$.Eq. / litre of sodium from the intracellular fluid would result in an elevation of serum concentration of sodium by $10 \mathrm{~m}$.Eq./litre : this was approximately the rise that occurred in Case 1 over a period of six days. The significant feature is that this sodium released from the cells was not lost in the urine in spite of a presumably adequate glomerular filtration at the time. 
The stimulus which initiates this cycle may be circulatory failure. If this is so, however, it is difficult to see why the sodium retention lasts so long after this is apparently corrected. It would be interesting to study the plasma volumes and plasma specific gravity in similar cases.

The information available in these cases is clearly incomplete, and much of what we have said is in the realm of speculation. Further and more detailed studies of the electrolyte pattern in extrarenal uraemia are desirable, with measurement of adrenocortical activity, particularly in regard to aldosterone output.

\section{Summary}

An unusual degree of sodium retention has been observed in three cases of extrarenal uraemia. The accompanying potassium depression, and, in one case, a high output of ketogenic steroids, suggests that the factor responsible for the sodium retention may be of adrenocortical origin.

We wish to thank Dr. A. W. D. Leishman for permission to publish, and Dr. A. Jordan and Dr. A. A. G. Lewis for encouragement and much helpful criticism in the preparation of this paper. We are also indebted to Mr. M. Levell for steroid estimations, and to members of the staff of the chemical pathology laboratories of Sheffield Royal Hospital and Sheffield Royal Infirmary for their co-operation in carrying out the other investigations.

\section{REFERENCES}

Allott, E. N. (1939). Lancet, 1, 1035.

Borst, J. G. G. (1948). Ibid., 1, 824.

Bull, G. M., Joekes, A. M., and Lowe, K. G. (1949). Ibid., 2, 229. Cort, J. H., and Matthews, H. L. (1954). Ibid., 1, 1202.

Engstrom, W. W., and Liebman, A. (1953). Amer. J. Med., 15, 180. Gibson, G., and Norymberski, J. K. (1954). Ann. rheum. Dis., 13, 59. Higgins, G., Lewin, W., O'Brien, J. R. P., and Taylor, W. H. (1951). Lancet, 1, 1295.

Iseri, L. T., McCau ghey, R. S., Alexander, L., Boyle, A. J., and Myers, G. B. (1952). Amer. J. med. Sci., 224, 135.

Jepson, R. P., Jordan, A., and Lovell, M. J. (1956). Brit. J. Surg., 43, 390 .

Leaf, A. (1956). Biochem. $J$ : 62, 241.

Lo Quesne, L. P., and Lewis, A. A. G. (1954). In Ciba Foundation Symposium on the Kidney, p. 193. Churchill, London.

Levell, M. J. Mitchell, F. L., Paine, C. G., and Jordan, A. (1957). Journal of Clinical Pathology, 10, 72.

Llaurado, J. G. (1955). Lancet, 1, 1295.

Luetscher, J. A., and Blackman, S. S. (1943). Ann. intern. Med., 18, 741.

Marriott, H. L. (1947). Brit. med. J., 1, 285.

Merrill, J. P. (1954). In Ciba Foundation Symposium on the Kidney, p. 177. Churchill, London.

Myers, G. B., and Iseri, L. T. (1955). Arch. intern. Med., 95, 503.

Natelso n, S., and Alexander, M. O. (1955). Ibid., 96,172

Prunty, F. T. G., McSwiney, R. R., and Mills, I. H.'(1955). Proc. roy. Soc. Med., 48, 629.

Schoolman, H. M., Dubin, A., and Hoffman, W. S. (1955). Arch. intern. Med., 95,15 .

Squires, R. D., Crosley, A. P., and Elkinton, J. R. (1951). Circulation, $4,868$.

Welt, L. G., Seldin, D. W., Nelson, W. P., German, W. J., and Peters, J. P. (1952). Arch intern. Med. 90, 355, 